\title{
Delta III reverse shoulder arthroplasty in the treatment of complex 3-and 4-part fractures of the proximal humerus: 6 to 42 months of follow up
}

\author{
Georg Mattiassich ${ }^{1 *}$, Lucian Lior Marcovici ${ }^{2}$, Rolf Michael Krifter ${ }^{3}$, Reinhold Ortmaier ${ }^{4}$, Peter Wegerer ${ }^{1}$ \\ and Albert Kroepfl'
}

\begin{abstract}
Background: There is a growing tendency for complex proximal humerus fractures (PHF) in osteoporotic patients to be treated with reverse shoulder arthroplasty (RSA). It has been proposed that RSA has more benefits than other treatment options. The aim of our study was to investigate preoperative characteristics as well as clinical and radiological outcomes in patients with complex 3- or 4-part PHF who had undergone primary RSA.

Methods: Patients with a minimum follow-up of 6 months who had undergone a primary RSA after 3- or 4-part PHF in the period between 2008 and 2011 were eligible for the study. Clinical records, X-rays and CT-scans were investigated and a clinical examination was performed. Disabilities of the Arm, Shoulder and Hand (DASH) score and Constant-Murley score (CMS) were calculated. Sixteen patients were examined as part of the study. The mean follow-up was 20 months (range 6-42 months). According to Codman-Hertel classification we encountered 15 Hertel " 12 " and 1 Hertel " 8 " type fractures.

Results: Thirty-two patients (27 female - 84.4\%) with a mean age of 72 years underwent operations to treat complex 3- and 4-part fractures of the proximal humerus. Sixteen patients were reexamined. In 14 cases the dominant upper extremity was on the right, in 2 cases it was on the left, in 6 cases the right side was affected and in 10 cases the left side was affected. The mean CMS was 54.8 (range 18-95) and the mean DASH was 37.5 (range 2.9-81). A trend was established between the CMS and dominance of the affected shoulder. The CMS was better if the affected shoulder was on the non-dominant side ( $p$-value 0.051). No statistical difference was noted between age and clinical outcome.
\end{abstract}

Conclusions: Our mid-term follow-up shows satisfying results in terms of the treatment of severe displaced fractures in elderly patients with RSA. RSA can provide immediate relief and good shoulder function in elderly patients. Nevertheless, the question of longevity of these implants remains to be observed.

Keywords: Reverse shoulder arthroplasty, Proximal humerus fracture, Joint prosthesis

\section{Background}

Vertebral fractures, hip fractures, distal forearm fractures and humeral fractures are the most common osteoporotic fractures. The average lifetime risk in a 50 year old Caucasian of experiencing a humeral fracture has been estimated at $12.9 \%$ for women and at $4.1 \%$ for men [1].

\footnotetext{
* Correspondence: georg.mattiassich@gmx.at

${ }^{1}$ Trauma Center Unfallkrankenhaus Linz, Teaching Hospital of the Paracelsus Medical University Salzburg, Garnisonstrasse 74017, Linz, Austria

Full list of author information is available at the end of the article
}

There is increasing incidence of such fractures due to the increasing mean age of the population and the higher levels of activity among the elderly. Palvanen et al. showed that in the over 60 age group in Finland the incidence of proximal humerus fractures tripled between 1970 and 1998 and they anticipate that this trend will continue until 2030 [2].

Possibilities for treating for such fractures range from conservative treatment to operative options such as the plate or nail fixation, humerus-block or other k-wire based

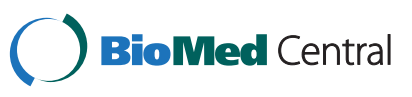


systems, hemiarthroplasty or the reversed shoulder arthroplasty (RSA) [3-5].

Grammont invented the RSA for rotator cuff tear arthropathies in 1985 [6]. The indication for PHF in the elderly as an alternative to hemiarthroplasty and plate fixation has broadened in recent years as the number of complications associated with osteosynthesis with unfavourable functional outcome is high in this group of patients due to osteoporotic bone structure as well as the high risk of avascular necrosis of the humeral head and the lack of sufficient rotator cuff [7].

There is a growing tendency for complex PHF in osteoporotic patients to be treated with RSA. It has been proved that patients treated with RSA are easier to mobilize, require less time in hospital and have a better functional outcome after 6 months compared with patients who have undergone other forms of treatment [8].

The unsolved questions of RSA are the need of refixation of the tubercles, the lack of retroversion and the lack of further solutions in case of failure, as we do not have many long-term results.

We set out to investigate preoperative characteristics as well as clinical and radiological outcomes in patients who had undergone a primary RSA as treatment for complex 3 or 4-part PHF in our department in the period from January 2008 to December 2011.

\section{Methods \\ Patients}

During the study period from January 2008 and December 2011, 32 patients (27 female - 84.4\%) underwent a primary RSA for proximal humerus fracture. The study was performed with the approval of the Institutional Review Board of the AUVA - Austrian social insurance for occupational risks. All patients were contacted in accordance with guidelines set up by the Committee and signed a consent form after being fully informed about the study.

\section{Clinical records and investigation}

All available X-rays and computer tomography scans (CTscans) were analyzed with regard to the type of fracture, the direction of dislocation, the length of posteromedial hinge and axis of dislocation. The fractures were classified according to the Neer-, the AO- and the Codman-Hertel classifications.

Clinical records were reviewed for information on patient demographics, co-morbidities, course of trauma, affected side, hand dominance and time to operation. Operation reports were analyzed with regard to duration of procedure, type and size of used prosthesis and the refixation of the tubercles. Rehabilitation protocols were evaluated on the start of active motion.

\section{Positioning and procedure}

All patients were positioned in the up-right beach chair position. All patients underwent the procedure using the cemented Delta Xtend ${ }^{\mathrm{Tm}}$ (DePuy-Johnson\&Johnson, Warsaw, IN) Reverse Shoulder System. Three highly experienced shoulder fellowship trained surgeons implanted all of the RSAs.

In all cases a Delta-split or deltopectoral approach was used. The approach depended on the direction of the dislocation, the type of fracture and the position of the dislocated head. Tuberosity refixation was attempted in all cases using non-absorbable sutures, which were fixed to the remaining humeral bone or where this was not possible without tension then to holes in the stem.

\section{Postoperative phase}

Patients were postoperatively immobilized with a Gilchrist-bandage, which remained in place for 4 to 6 weeks after the operation. Start of active assisted motion was defined by the primary surgeon and depending on intraoperative stability began from the 2nd to the 10th day post operation. Our physiotherapists mobilized the patients' shoulders. The patients were regularly examined in our outpatient clinic. A rehabilitation program under medical surveillance was continued for several weeks until maximum recovery was attained.

\section{Protocol}

In the period between September and December 2011, 16 patients were available and were examined clinically and radiologically for study purposes. The radiological reassessment included X-ray of both shoulders in anteroposterior (AP) and Y-view. The images were analyzed and focused on loosening of the prosthesis, healing of tubercles and notching. Partial resorption of the tubercle was

\section{Table 1 Characteristics of study patients}

\begin{tabular}{lc}
\hline Details & Patients \\
\hline Patients & 32 \\
Women/Man (\%) & $27(84.4 \%) / 5(15.6 \%)$ \\
Excluded From The Study & 16 patients \\
Follow up < 6 month & 7 patients \\
Did not respond on call & 2 patients \\
Dementia & 2 patients \\
Decease & 1 patient \\
Prosthesis explanation & 1 patient \\
Refused entering the study & 1 patient \\
Entered In The study & 16 patients \\
Mean Age (range) & 72 years (60-89 years) \\
Mean BMl (range) & 28.9 kg/m ${ }^{2}$ \\
Mean Follow up (range) & 20 months (6-42 months)
\end{tabular}


Table 2 Results and other characteristics of patients

\begin{tabular}{|c|c|c|c|c|c|c|c|c|}
\hline & $\begin{array}{l}\text { Age at } \\
\text { trauma }\end{array}$ & $\begin{array}{l}\text { Age at follow } \\
\text { up }\end{array}$ & DASH & $\begin{array}{l}\text { Constant-Murley- } \\
\text { score }\end{array}$ & $\begin{array}{l}\text { Time operation } \\
(\mathrm{min})\end{array}$ & $\begin{array}{l}\text { Months } \\
\text { treatment }\end{array}$ & $\begin{array}{l}\text { Follow- } \\
\text { up }\end{array}$ & $\begin{array}{l}\text { Deficit } \\
\text { abduction }\end{array}$ \\
\hline $\mathrm{N}$ of Cases & 16 & 16 & 16 & 16 & 16 & 16 & 16 & 16 \\
\hline Minimum & 60 & 63 & 2,9 & 18 & 80 & 1 & 6 & 0 \\
\hline Maximum & 89 & 90 & 81 & 95 & 142 & 14 & 42 & 100 \\
\hline Range & 29 & 27 & 78,1 & 77 & 62 & 13 & 37 & 100 \\
\hline $\begin{array}{l}\text { Arithmetic } \\
\text { Mean }\end{array}$ & 72 & 73,75 & 37,5 & 54,75 & 108 & 5,2 & 19,8 & 37,5 \\
\hline $\begin{array}{l}\text { Standard } \\
\text { Deviation }\end{array}$ & 8 & 7,6 & 24 & 19,1 & 18,6 & 3,8 & 11,9 & 34,7 \\
\hline
\end{tabular}

defined as loosening of 25 to $50 \%$ in the initial height of the tubercle and full resorption defined as more than $50 \%$ of initial height.

The clinical examination included measurement of the range of motion of both shoulders, the grip strength of both hands measured using the Jamar dynamometer. Pain experienced in motion and under load was assessed using the visual analogue scale (VAS).

The Disabilities of the Arm, Shoulder and Hand (DASH) score and the Constant-Murley score (CMS) forms were completed. Upon completion of the radiological and clinical examination the parameters were recorded in the case report form and computerized for statistical analysis.

\section{Statistical analysis}

Quantitative data is given as "minimum", "maximum", "range", "arithmetic mean" and "standard deviation". Correlations were calculated using the Pearson Correlation coefficient. The Kruskal-Wallis one-way analysis of variance and Mann Whitney $U$ test were used for non-parametric testing. Systat 12 (Systat Software, Inc., Chicago, IL) was used to perform statistical calculations.

\section{Follow-up study}

Sixteen patients were excluded from the study (7 due to follow up of less than 6 months, 4 did not respond, 2 due to dementia, 1 died, 1 had an explantation of the prosthesis after infection, 1 declined to participate in the study). The mean age of the study population at trauma was 72.0 years (range from 60 to 89 years). The mean body mass index (BMI) was $28.9 \mathrm{~kg} / \mathrm{m}^{2}$ (Table 1). The mean follow up was 20 months (median 17 months, range 6-42 months). An overview of results and other characteristics of patients observed in the follow up study is provided in Table 2.

The cause of trauma was a fall of less than 2 meters in 11 cases, a fall above 2 meters in one patient, 2 high velocity traffic accidents (at more than $50 \mathrm{~km} / \mathrm{h}$ ) and 1 low velocity traffic accident. Ten of the 16 patients were affected on their dominant side. The time to operation was 8.5 days (median of 7 , range $0-26$ days). Three patients were operated on after more than 20 days because patients refused to undergo an RSA as recommended by their surgeon. The other patients were operated on within the first 9 days.

All fractures were attributed to $\mathrm{C}$-type according to AO-classification. According to Neer classification, 15 4-part fractures and 13 -part fracture were encountered. According to Codman-Hertel classification, we encountered 15 Hertel "12" and 1 Hertel " 8 " type fractures (Figures 1, 2, 3). Eight fractures were dislocated anteriorly and 8 posteriorly. 14 had a posteromedial metaphyseal hinge greater than $8 \mathrm{~mm}$. Seven humeral heads were dislocated in valgus and in 3 cases the head presented splitting of more than $20 \%$.

The deltopectoral approach was chosen in 2 cases due to the proximity of the humeral head posteriorly to the

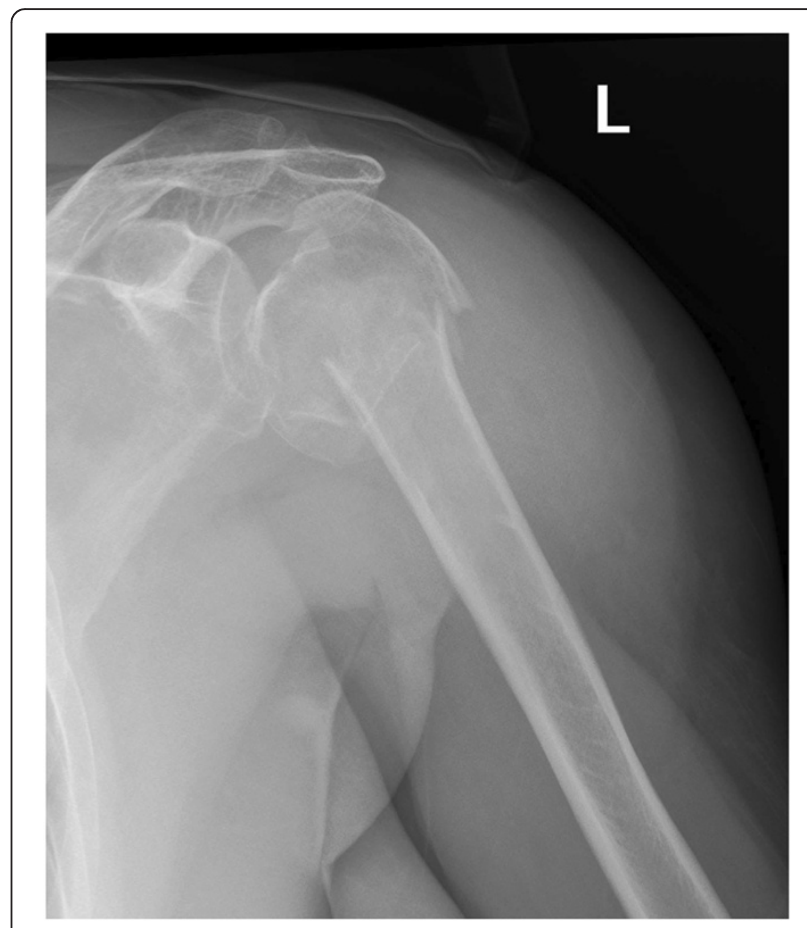

Figure $1 \mathrm{X}$-ray after trauma (a.-p.-view). 


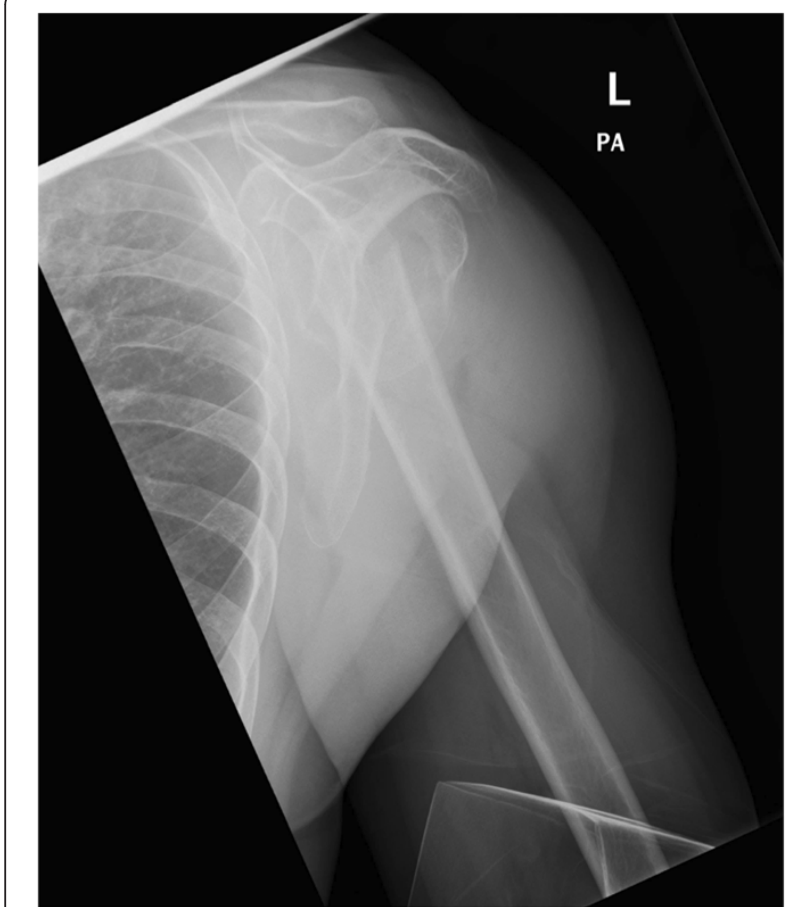

Figure 2 X-ray after trauma (Y-view).

subscapularis muscle. A well-established cemented reverse monobloc prosthesis (Delta Xtend ${ }^{\mathrm{m}}$ (DePuyJohnson\&Johnson, Warsaw, IN) was used in all cases (Figures 4 and 5). Retroversion was set to $0^{\circ}$. Four screws were used for the fixation of the metaglene. The

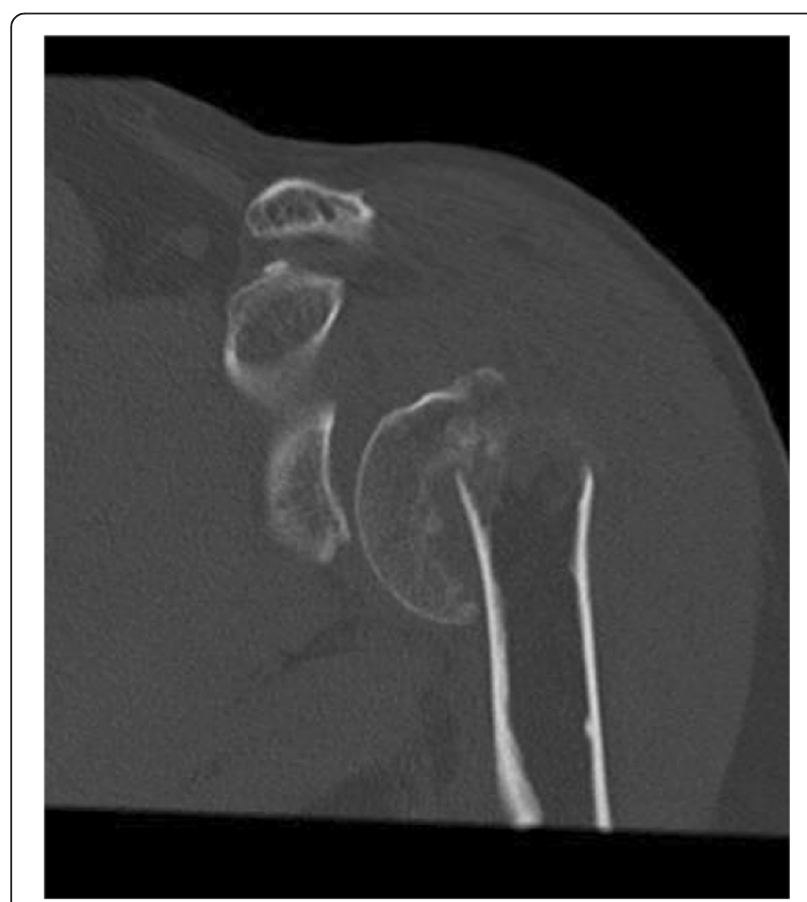

Figure 3 CT-scan after trauma.

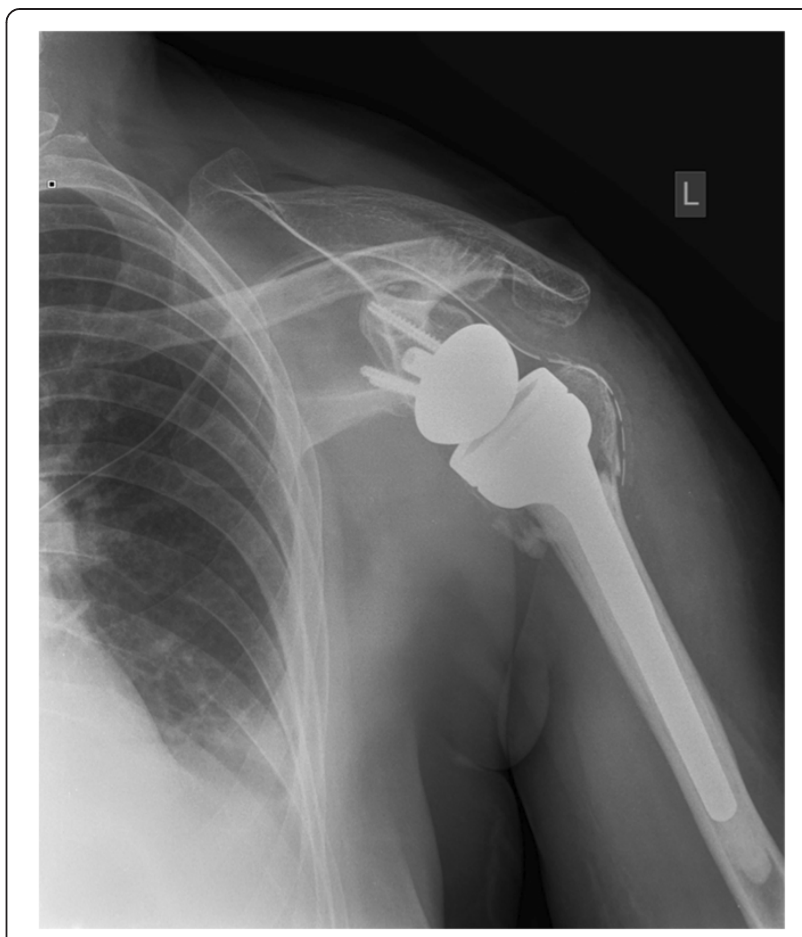

Figure 4 X-ray after implantation of reverse shoulder arthroplasty with refixation of greater tuberosity (a.-p.-view).

metaglene was positioned as low as possible and tilted slightly downwards. The size of the glenosphere was between 38 and 42 .

Strong and stable refixation of the greater and lesser tuberosity was attempted in all cases using strong sutures around the neck of the prosthesis (Figures 4 and 5). Bone grafting was not needed in any of the patients. The mean operation time was 108 minutes (median $107 \mathrm{~min}$, range 80 to $142 \mathrm{~min}$ ).

Mean hospitalization time was 19 days (range 10-38 days). Three of the patients stayed in hospital for more than 35 days. This was due to a complex clinical situation as they were severe polytrauma patients. The mean time between the operation and the start of active movement was 12.5 days (range 1-28 days). 4 patients had started active movement after more than 15 days due to their compromised clinical situation.

\section{Results}

\section{Complications}

We experienced one case of transient axillary nerve impairment, one case of superficial wound infection, one deep infection that underwent revision surgery, one dislocation which also underwent revision surgery with a thicker inlay and one patient presented persisting pain resistant to medical therapy. This patient suffers from major depression. 


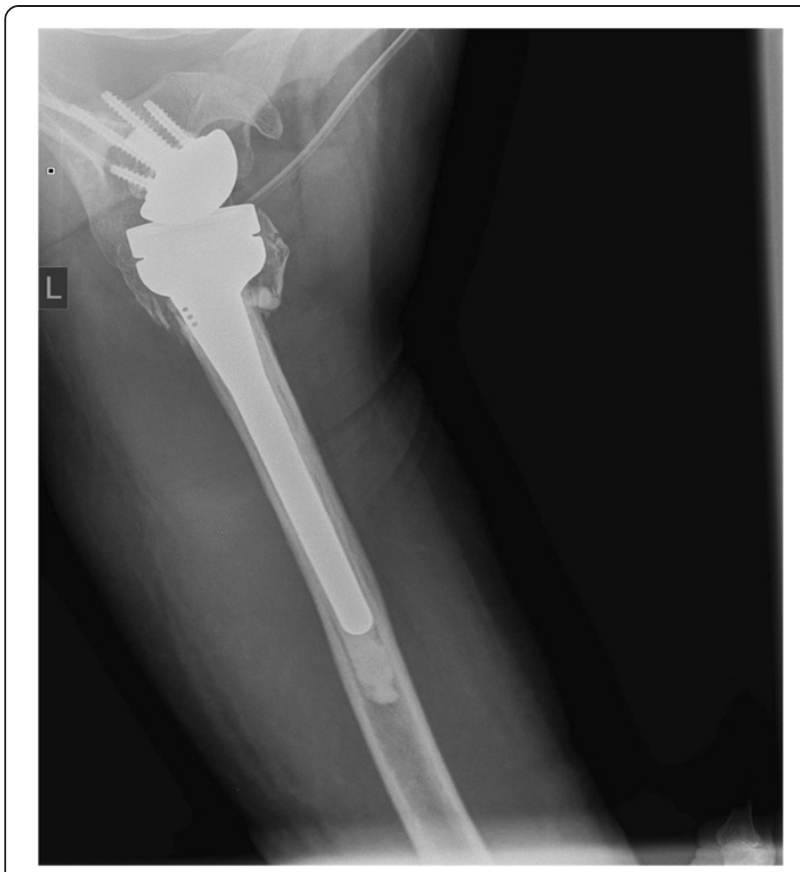

Figure 5 X-ray after implantation of reverse shoulder arthroplasty (axial-view).

\section{Clinical results}

The postoperative mean range of motion at follow up was: abduction $106.9^{\circ}\left(50^{\circ}-180^{\circ}\right)$; flexion $115.6^{\circ}\left(50^{\circ}-170^{\circ}\right)$; extension $36.3^{\circ}\left(20^{\circ}-60^{\circ}\right)$; external rotation $20.6^{\circ}\left(0^{\circ}-50^{\circ}\right.$ internal rotation $50.3^{\circ}\left(30^{\circ}\right.$ to $\left.70^{\circ}\right)$ (Figures $\left.6,7,8,9,10,11\right)$. The grip strength measured using the Jamar dynamometer on the affected side was: $80.3 \mathrm{mmHg}(30-180 \mathrm{mmHg})$. The Visual Analog Score (VAS) was: 2.5 (0-8).

The CMS was 54.8 (range 18-95), the DASH was 37.5 (range 2.9-81). There is correlation between the two scores (Pearson correlation -0.879). However, less correlation was observed between age, abduction deficits and the two scores (Table 3).

A trend was established between the CMS and the dominance of the affected shoulder. The CMS was better if the affected shoulder was on the non-dominant side (p-value 0.051 - Table 4). No significant statistical difference was noted between age and clinical outcome. We encountered notching grade I in 7 patients. There were no signs of notching in 9 patients. We encountered no acromion fractures and no non-unions at the fracture site.

\section{Radiological results}

A displacement of the tuberosities was not noted (Figures 12 and 13). Partial resorption was seen in 8 (50\%) cases. One patient had a full resorption of the tubercle.

We encountered 7 cases with stage 1 scapular notching. It did not influence the function or pain in any of these patients. We did not observe any heterotopic ossification in our study.

\section{Discussion}

The treatment of complex 3- and 4-part fractures of the proximal humerus with high risk of avascular necrosis represents a difficult problem for the surgeon. In our experience and according to the literature, methods such as plate or nail fixation may have a significant complication rate and unpredictable functional outcome.

Our mid-term follow-up shows satisfying results for the treatment of severe displaced fractures in elderly patients using RSA. According to our results, RSA can provide immediate relief and good shoulder function for elderly patients with severe PHF.

Nevertheless, the question of longevity of these implants remains to be observed. Long term follow-up studies for RSA as the primary treatment of PHF are necessary in order to assess the incidence of late or long-term

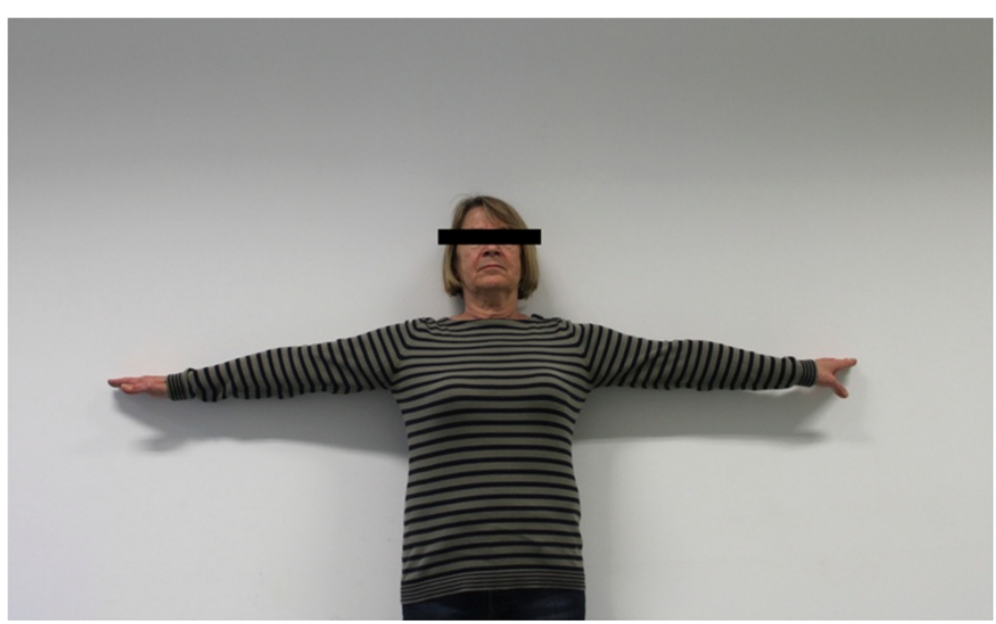

Figure 6 Clinical outcome with satisfying result after one year in abduction (affected shoulder left side). 


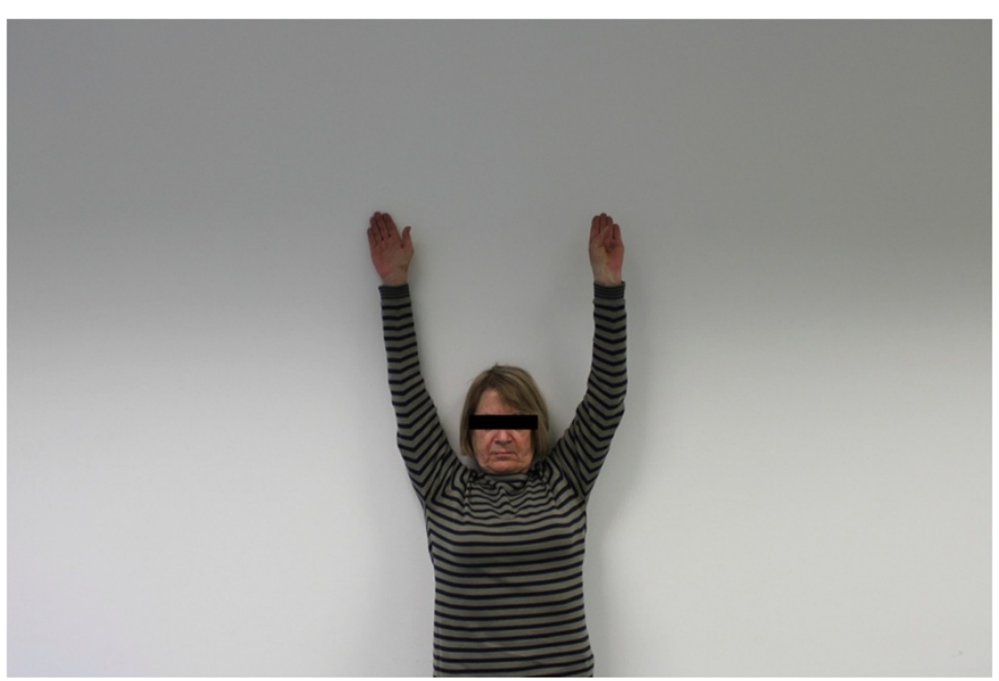

Figure 7 Clinical outcome with satisfying result after one year in maximum abduction (affected shoulder left side).

complications with respect to component longevity, loosening, duration of pain relief and reduction of strength and ROM.

In a study by Favard et al. [9] the authors found in a population with a mean age of 73 years a decrease in the relative CMS from $88 \%$ at under five years to $78 \%$ after more than 9 years. Additionally, the authors found that $72 \%$ of the patients had a CMS of less than 30 (defined as

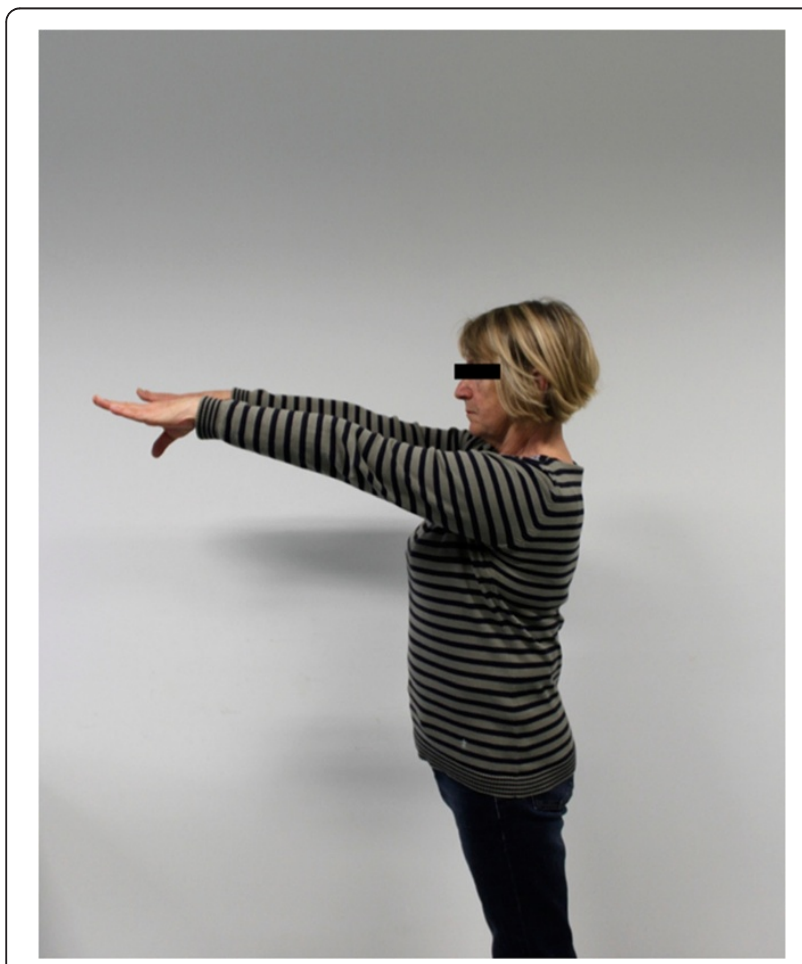

Figure 8 Clinical Clinical outcome with satisfying result after one year in flexion (affected shoulder left side).

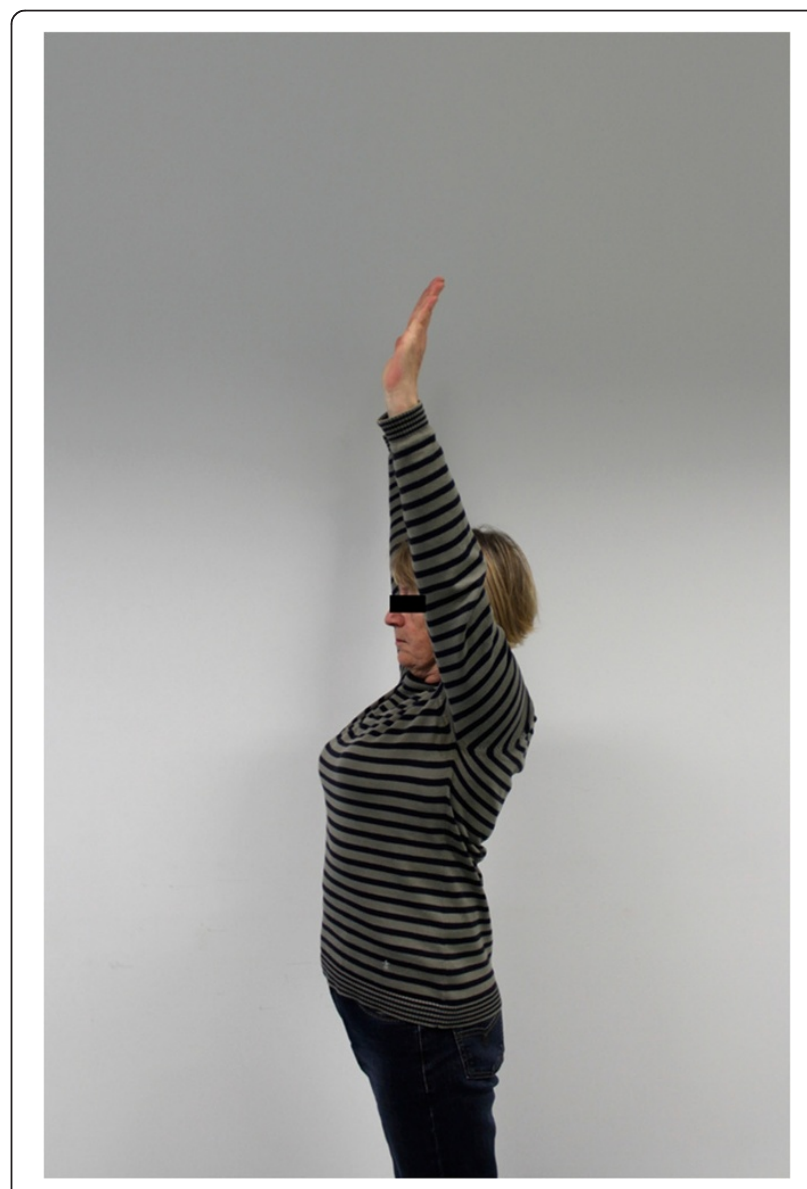

Figure 9 Clinical outcome with satisfying result after one year in maximum flexion (affected shoulder left side). 


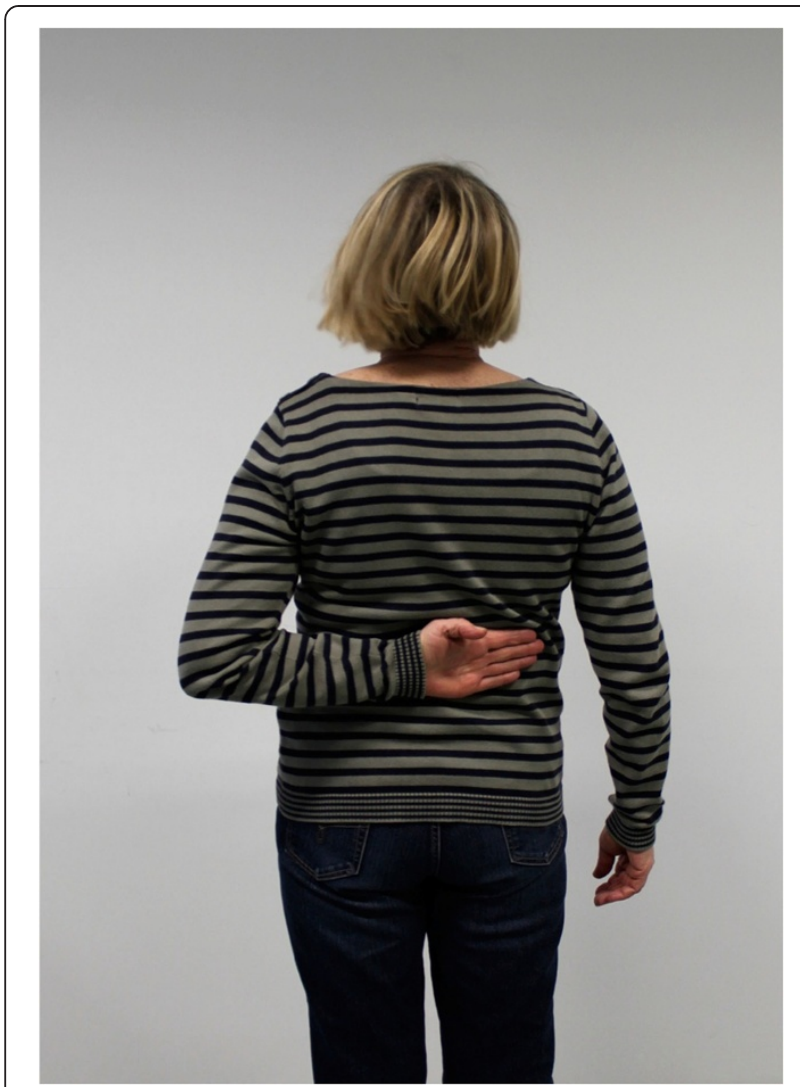

Figure 10 Clinical outcome with satisfying result after one year in internal rotation (affected shoulder).

an end-point) after 10 years. In another study by Guery et al. [10] a survivorship of $58 \%$ after 10 years is reported.

In patients younger than 65 years improved function is reported to be maintained for up to 10 years [11].

Patients with severely displaced 3- or 4-part proximal humerus fractures are at high risk of suffering avascular necrosis of the humeral head [12].

Open reduction and internal fixation (ORIF) is often difficult to achieve, as fragment displacement, comminution and osteoporotic bone quality act as limiting factors.

For these reasons, humeral head replacement is indicated when ORIF is not possible, or in cases where there is a high risk of avascular necrosis of the humeral head according to Hertel's studies $[7,13,14]$.

Satisfactory shoulder function after hemiarthroplasty can be inadequate due to the problem of tuberosity fixation and preexisting rotator cuff disease with or without arthopathy especially in older patients. Poor shoulder function after hemiarthroplasty is often associated with nonunion, displacement and resorption of tuberosity fragments, which often leads to revision arthroplasty using an inverse design [15].

While hemiarthroplasty has been seen to produce satisfactory pain control there are problems with limited range

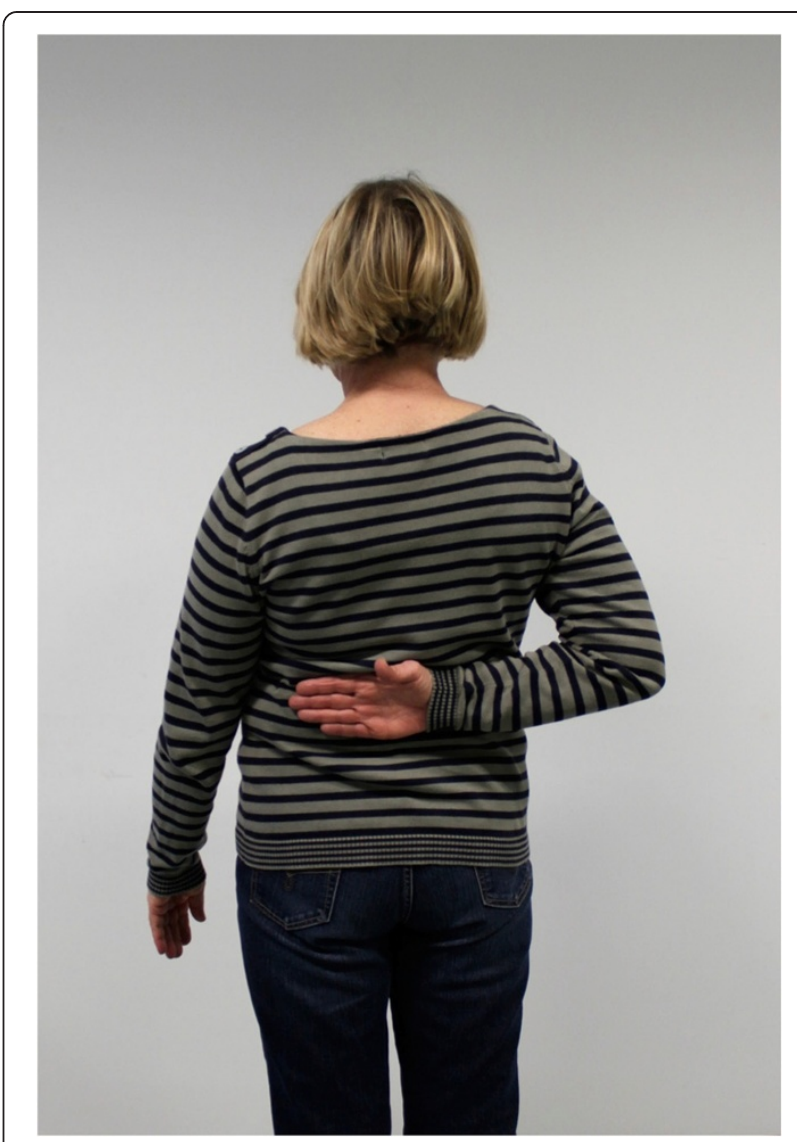

Figure 11 Clinical outcome with satisfying result after one year in flexion (non-affected shoulder).

of motion and shoulder function when it is used as a treatment for severe proximal humerus fractures $[4,16]$.

In a study by Boons et al. [17] the authors investigated in a randomized controlled trial the outcome after hemiarthroplasty was used to treat four-part fractures in patients older than 60 years. In 25 patients treated with hemiarthroplasty they established a mean CMS of 64 , a mean abduction of $77^{\circ}$ and anterior flexion of $98^{\circ}$. In two patients they found postoperative tuberosity resorption. However, they noted that there may have been more disrupted tuberosities which were not observed on plain radiographs.

Table 3 Correlation between DASH, Constant-Murley-score and abduction deficit

\begin{tabular}{lllll}
\hline & $\begin{array}{l}\text { Age at follow } \\
\text { up }\end{array}$ & DASH & CMS & $\begin{array}{l}\text { Abduction } \\
\text { deficit }\end{array}$ \\
\hline Age at follow up & 1,000 & & & \\
DASH & $-0,386$ & 1,000 & & \\
CMS & 0,168 & $-0,879$ & 1,000 & \\
$\begin{array}{l}\text { Abduction } \\
\text { deficit }\end{array}$ & $-0,048$ & 0,484 & $-0,627$ & 1,000 \\
\hline
\end{tabular}




\begin{tabular}{|c|c|c|}
\hline Mann-Whitney U test statistic & $:$ & 48,000 \\
\hline$p$-value & : & 0,051 \\
\hline Chi-square Approximation & $:$ & 3,817 \\
\hline$d f$ & $:$ & 1 \\
\hline
\end{tabular}

Comparative literature contrasting the functional outcome of RSA to hemiarthroplasty in the management of PHF is relatively limited. However, functional outcomes showed no significant difference between these two methods and were even higher in the RSA group according to CMS $[18,19]$.

In a comparative study by Garrigues et al. [20] the authors investigated 23 patients of whom 12 had undergone hemiarthroplasty and 11 had undergone reverse total shoulder arthroplasty for proximal humeral fractures in elderly patients. The mean ASES score of the RSA group was 81.1 (range 75-88) and was significantly better than the hemiarthroplasty group with a score of 47.4 points (range $30-81)(\mathrm{p}<0.05)$. The mean forward elevation was $121^{\circ}$ (range $90^{\circ}-145^{\circ}$ ) for the RSA group and $91^{\circ}$ (range $30-140^{\circ}$ ) for the hemiarthroplasty group, respectively $(\mathrm{p}<0.05)$.

In our study, results for RSA compare favourably with than the functional outcome for hemiarthroplasty in such

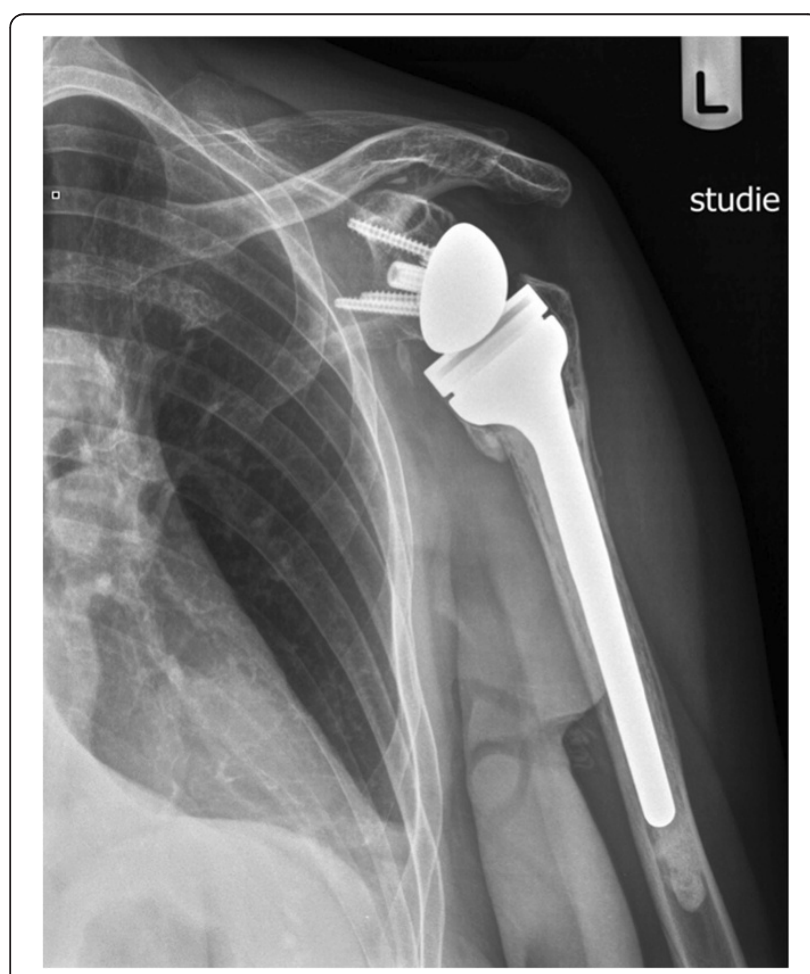

Figure $12 \mathrm{X}$-ray one year after implantation of reverse shoulder arthroplasty with healed greater tuberosity (a.-p.-view).

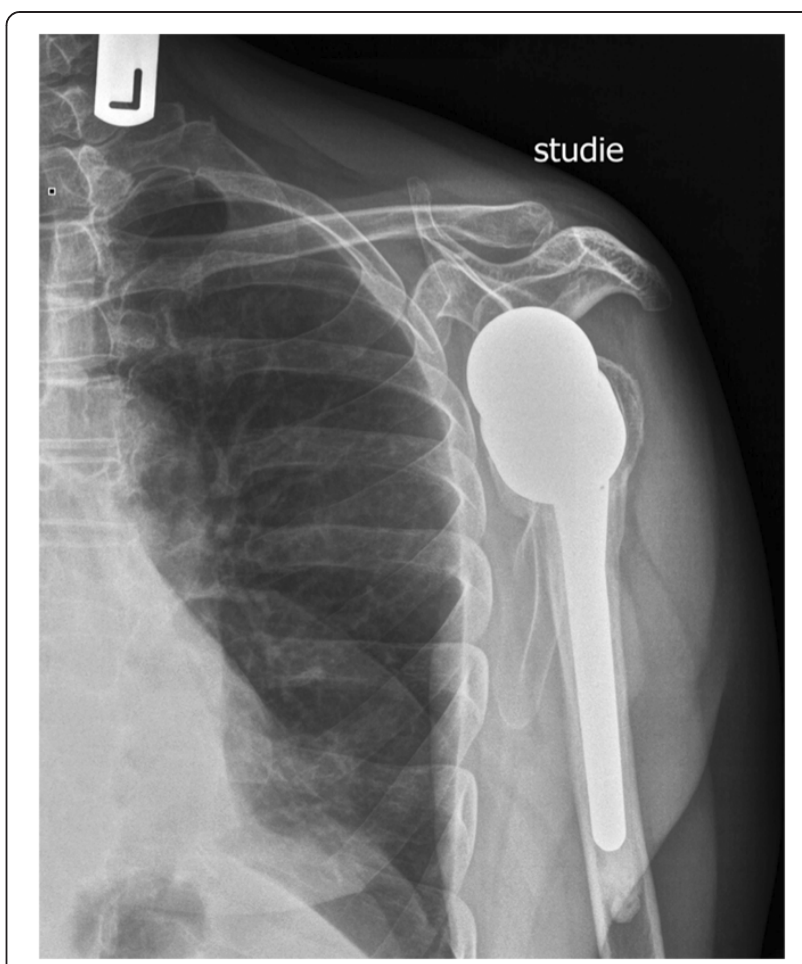

Figure $13 \mathrm{X}$-ray one year after implantation of reverse shoulder arthroplasty (Y-view).

patients. Our own results are encouraging and correlate with previously published reports from other trauma centers.

Proximal humeral head fractures often occur in lowdemand patients, who can have multiple comorbidities and reduced requirements with regard to shoulder function. In this population group, the primary goal of treatment is pain-free shoulder mobility that provides good function for daily activities and personal hygiene requirements.

Use of primary RSA in the treatment of complex 3- and 4-part fractures of the humeral head remains controversial in Austria. It was previously not routinely performed in our trauma center. There are also certain limitations associated with RSA - the age and the comorbidities of the patients, for example, must of course always be taken into account.

Since 2008, after experiencing unsatisfying functional outcomes for treatment with hemiarthroplasty or plate fixation, we decided to treat patients over 65 years of age or low-demand patients with complex 3- and 4-part PHF and high risk for avascular necrosis and/or with preexisting comorbidities with primary RSA. Our preferred form of treatment would otherwise be ORIF using a plate or alternative methods such as humerus-block in selected cases.

As we have only operated on the worst forms of fractures in elderly or low-demand patients, we achieved a relatively satisfying functional outcome score of 54.8 in CMS, which is comparable to those described in the published literature [4,12,18,21]. 
We attempted to repair the tuberosities in all cases as there is evidence that healing of the tuberosities is associated with better functional outcome [5,22-24]. Satisfactory outcome also depends on the positioning of the glenosphere in the lower part of the glenoid in order to prevent scapular notching $[21,25,26]$.

The difference in the functional outcome by comparing the ROM, the grip strength and the pain relief in the non-affected and the affected shoulder did not have a major influence on day-to-day activities of the patients as the CMS and the DASH scores showed good results. Our results for pain reduction and range of motion correlate with results observed in previously published literature for this procedure $[10,21,27,28]$.

We observed good functional results during rehabilitation with an early start of passive and active motion although a sling fixation was used for 4-6 weeks. This can also be associated with improved acceptance of the implant by the patient as RSA provides immediate stability of the shoulder.

We encountered some system related complications including a case of transient axillary nerve impairment, which resolved completely after 1 month without additional therapy. A case of dislocation of the shoulder lead to revision with a thicker inlay. The patient did not experience any further instability of the shoulder. We also observed 2 cases of infection. One was a superficial infection that was treated with debridement and did not lead to further complications. The other was a deep infection related to the prosthesis that led to explantation of the prosthesis in a multimorbid patient.

The study has several limitations. Firstly, not all of our operated patients fulfilled the inclusion criteria and we therefore had a highly selected group of patients. Secondly, the average follow up time of 20 months is relatively short. Thirdly, there was a lack of comparison group for comparison of results for ORIF or hemiarthroplasty for example.

\section{Conclusion}

Our mid-term follow-up shows satisfying results for the treatment of severe displaced fractures in elderly patients using RSA. RSA can provide immediate relief and good shoulder function in elderly patients. Nevertheless, the question of longevity of these implants remains to be observed.

\section{Competing interests}

The authors declare that they have no competing interests.

\section{Authors' contributions}

GM was responsible for conception, design, acquisition of data, analysis and interpretation of data and drafting the manuscript. LM has been involved in drafting the manuscript and interpretation of data. RO has been involved in critical revision of the manuscript and has improved the discussion section regarding complications associated with RSA. PW participated in the design of the study and was responsible for clinical management of the patients. RK has been involved in critical revision of the manuscript with regard to important intellectual content. AK provided general supervision of the research group and was involved in critical revision of the manuscript. All authors read and approved the final manuscript.

\section{Acknowledgement}

The authors thank Ernst Foltin for his statistical support.

\section{Author details}

${ }^{1}$ Trauma Center Unfallkrankenhaus Linz, Teaching Hospital of the Paracelsus Medical University Salzburg, Garnisonstrasse 74017, Linz, Austria.

2Department of Orthopaedic and Trauma Surgery, "Sapienza" University of Rome, Piazzale Aldo Moro 500185, Rome, Italy. ${ }^{3}$ General and Orthopedic Hospital LKH Stolzalpe, Teaching hospital of Graz Medical University, Stolzalpe 388852, Stolzalpe, Austria. ${ }^{4}$ Department of Trauma Surgery, Paracelsus Medical University and Salzburger Landeskliniken, Müllner Hauptstraße 485020, Salzburg, Austria.

Received: 10 February 2013 Accepted: 5 August 2013

Published: 8 August 2013

\section{References}

1. Johnell O, Kanis J: Epidemiology of osteoporotic fractures. Osteoporosis international: a journal established as result of cooperation between the European Foundation for Osteoporosis and the National Osteoporosis Foundation of the USA 2005, 16(Suppl 2):3-7.

2. Palvanen M, Kannus $P$, Niemi S, Parkkari J: Update in the epidemiology of proximal humeral fractures. Clin Orthop Relat Res 2006, 442:87-92.

3. Aaron D, Shatsky J, Paredes JC, Jiang C, Parsons BO, Flatow EL: Proximal humeral fractures: internal fixation. J Bone Joint Surg Am 2012, 94(24):2280-2288.

4. Antuna SA, Sperling JW, Cofield RH: Shoulder hemiarthroplasty for acute fractures of the proximal humerus: a minimum five-year follow-up. J Shoulder Elbow Surg 2008, 17(2):202-209.

5. Klein M, Juschka M, Hinkenjann B, Scherger B, Ostermann PA: Treatment of comminuted fractures of the proximal humerus in elderly patients with the Delta III reverse shoulder prosthesis. J Orthop Trauma 2008, 22(10):698-704.

6. Grammont PM, Trouilloud P, Laffay JP, Deries X: Etude et realisation d'une novelle prothese d'epaule. Rhumatologie 1987, 39:17-22.

7. Bastian JD, Hertel R: Osteosynthesis and hemiarthroplasty of fractures of the proximal humerus: outcomes in a consecutive case series. J Shoulder Elbow Surg 2009, 18(2):216-219.

8. Boyle MJ, Youn SM, Frampton CM, Ball CM: Functional outcomes of reverse shoulder arthroplasty compared with hemiarthroplasty for acute proximal humeral fractures. J Shoulder Elbow Surg 2013, 22(1):32-37.

9. Favard L, Katz D, Colmar M, Benkalfate T, Thomazeau H, Emily S: Total shoulder arthroplasty - arthroplasty for glenohumeral arthropathies: results and complications after a minimum follow-up of 8 years according to the type of arthroplasty and etiology. Orthop Traumatol Surg Res 2012, 98(4 Suppl):S41-47.

10. Guery J, Favard L, Sirveaux F, Oudet D, Mole D, Walch G: Reverse total shoulder arthroplasty. Survivorship analysis of eighty replacements followed for five to ten years. J Bone Joint Surg Am 2006, 88(8):1742-1747.

11. Ek ET, Neukom L, Catanzaro S, Gerber C: Reverse total shoulder arthroplasty for massive irreparable rotator cuff tears in patients younger than 65 years old: results after five to fifteen years. J Shoulder Elbow Surg 2013

12. Reitman RD, Kerzhner E: Reverse shoulder arthoplasty as treatment for comminuted proximal humeral fractures in elderly patients. Am J Orthop (Belle Mead NJ) 2011, 40(9):458-461.

13. Bastian JD, Hertel R: Initial post-fracture humeral head ischemia does not predict development of necrosis. J Shoulder Elbow Surg 2008, 17(1):2-8.

14. Hertel $R$, Hempfing A, Stiehler M, Leunig M: Predictors of humeral head ischemia after intracapsular fracture of the proximal humerus. J Shoulder Elbow Surg 2004, 13(4):427-433.

15. Ortmaier R, Resch H, Matis N, Blocher M, Auffarth A, Mayer M, Hitzl W, Tauber M: Reverse shoulder arthroplasty in revision of failed shoulder arthroplasty-outcome and follow-up. Int Orthop 2013, 37(1):67-75. 
16. Kontakis G, Koutras C, Tosounidis T, Giannoudis P: Early management of proximal humeral fractures with hemiarthroplasty: a systematic review. J Bone Joint Surg Br 2008, 90(11):1407-1413.

17. Boons HW, Goosen JH, Van Grinsven S, Van Susante JL, Van Loon CJ: Hemiarthroplasty for humeral four-part fractures for patients 65 years and older: a randomized controlled trial. Clin Orthop Relat Res 2012, 470(12):3483-3491.

18. Gallinet D, Clappaz P, Garbuio P, Tropet Y, Obert L: Three or four parts complex proximal humerus fractures: hemiarthroplasty versus reverse prosthesis: a comparative study of 40 cases. Orthop Traumatol Surg Res 2009, 95(1):48-55.

19. Young SW, Segal BS, Turner PC, Poon PC: Comparison of functional outcomes of reverse shoulder arthroplasty versus hemiarthroplasty in the primary treatment of acute proximal humerus fracture. ANZ I Surg 2010, 80(11):789-793.

20. Garrigues GE, Johnston PS, Pepe MD, Tucker BS, Ramsey ML, Austin LS: Hemiarthroplasty versus reverse total shoulder arthroplasty for acute proximal humerus fractures in elderly patients. Orthopedics 2012, 35(5):703-708

21. Lenarz C, Shishani Y, McCrum C, Nowinski RJ, Edwards TB, Gobezie R: Is reverse shoulder arthroplasty appropriate for the treatment of fractures in the older patient? Early observations. Clin Orthop Relat Res 2011, 469(12):3324-3331.

22. Bufquin T, Hersan A, Hubert L, Massin P: Reverse shoulder arthroplasty for the treatment of three- and four-part fractures of the proximal humerus in the elderly: a prospective review of 43 cases with a short-term follow-up. $J$ Bone Joint Surg Br 2007, 89(4):516-520.

23. Cazeneuve JF, Cristofari DJ: [Grammont reversed prosthesis for acute complex fracture of the proximal humerus in an elderly population with 5 to 12 years follow-up]. Rev Chir Orthop Reparatrice Appar Mot 2006, 92(6):543-548.

24. Levy JC, Badman B: Reverse shoulder prosthesis for acute four-part fracture: tuberosity fixation using a horseshoe graft. I Orthop Trauma 2011, 25(5):318-324.

25. Cazeneuve JF, Cristofari DJ: Delta III reverse shoulder arthroplasty: radiological outcome for acute complex fractures of the proximal humerus in elderly patients. Orthop Traumatol Surg Res 2009, 95(5):325-329.

26. Cazeneuve JF, Cristofari DJ: Long term functional outcome following reverse shoulder arthroplasty in the elderly. Orthop Traumatol Surg Res 2011, 97(6):583-589.

27. Boileau P, Watkinson D, Hatzidakis AM, Hovorka I: Neer Award 2005: The Grammont reverse shoulder prosthesis: results in cuff tear arthritis, fracture sequelae, and revision arthroplasty. J Shoulder Elbow Surg 2006, 15(5):527-540

28. Cuff D, Pupello D, Virani N, Levy J, Frankle M: Reverse shoulder arthroplasty for the treatment of rotator cuff deficiency. J Bone Joint Surg Am 2008, 90(6):1244-1251.

doi:10.1186/1471-2474-14-231

Cite this article as: Mattiassich et al:: Delta III reverse shoulder arthroplasty in the treatment of complex 3- and 4-part fractures of the proximal humerus: 6 to 42 months of follow up. BMC Musculoskeletal Disorders $201314: 231$.

\section{Submit your next manuscript to BioMed Central and take full advantage of:}

- Convenient online submission

- Thorough peer review

- No space constraints or color figure charges

- Immediate publication on acceptance

- Inclusion in PubMed, CAS, Scopus and Google Scholar

- Research which is freely available for redistribution 